\title{
The legal implication of certain interventions prohibited by law in the United Kingdom and Slovakia - a review
}

\author{
Anna Packová, Adam Rogers, Daniela Takáčová \\ University of Veterinary Medicine and Pharmacy in Kosice, Department of Public Veterinary Medicine \\ and Animal Welfare, Kosice, Slovak Republic
}

Received June 23, 2020

Accepted December 21, 2020

\begin{abstract}
Mutilation of dogs is an emotive and controversial subject for veterinarians and animal keepers. The elective docking of a dog's tail is illegal under both UK and Slovak law except for specific breeds that are intended to be used for specific purposes while the elective cropping of dogs' ears is illegal under all circumstances. In the EU, there is much variation between countries with some having a total ban on these procedures and others allowing elective ear cropping specifically. Under the current UK as well as Slovak legislation there is no legal requirement for a central monitoring of the number of docking procedures undertaken, therefore it is not possible to analyse the efficacy of the legislation, specifically, the monitoring of the number of legally docked dogs that are not eventually used for the purpose for which their exemption was granted. There is also no certification scheme for dogs undergoing ear cropping legally in EU countries that permit it. It is suggested that greater monitoring be implemented of the eventual use of docked dogs and the EU granting proof of legality to ear cropped dogs in order to understand how great a risk is posed by illegal docking and cropping procedures.
\end{abstract}

Legislation, procedures, pure breeds, working dogs

Animal welfare is a key concern for many people and legislators are faced with the task of drafting legislation that would ensure minimum welfare standards while recognising the various roles animals play in human society.

Of all the species domesticated by humans, the domestic dog (Canis lupus familiaris) has a long history of domestication as both a companion animal and a working animal. This contrasting relationship leads to a conflict between the perceptions of minimum welfare standards imposed by different factions of society.

Historically, dogs were used for tasks as varied as hunting, guarding, herding and protection, among others, and the recognition between a dog's physical appearance and its functional abilities led to the development of many primitive breeds through the selection of individual dogs with desirable traits (Wayne and Ostrander 1999). Phenotypically each is unique and it was these phenotypic differences that allowed for selection of the individuals that were best suited to the role they were to play in human society (Pedersen et al. 2013). A key component of the development and physical appearance of the breed is the elective modification of its body, most notably through caudectomy, i.e. the surgical removal of all or part of the tail, herein referred to as 'docking' (Bennett and Perini 2003) and the surgical cosmetic otoplasty, referred to as 'cropping' (Cosenza 1988).

The issue of cosmetic alteration, notably the docking of tails and cropping of ears provides a potential welfare concern for dogs and a legal, moral and ethical concern for veterinarians.

Under the Slovakian and UK laws, ear cropping is illegal unless for medical reasons, however, the importation of dogs with ears cropped in some countries is not illegal. The docking of a dog's tail is illegal in the UK unless the dog is certified as a working dog. Currently the onus lies on the owner of docked puppies to provide this evidence, however,

Address for correspondence:

Daniela Takáčová

Department of Public Veterinary Medicine and Animal Welfare

University of Veterinary Medicine and Pharmacy in Kosice

Phone: +421915984608

Komenskeho 73, 04181 Kosice, Slovak Republic 
the evidence is worded such that while the dog may be intended to be used for the specified work, the owner is under no obligation to keep the dog for working purposes only and may legally sell the dog to another owner with no intention of using it for such purposes. Slovakian law allows tail docking in dogs of certain pure breeds if this procedure takes place within 14 days after a puppy is born.

The ambiguity of this legislation suggests that veterinarians may be unwillingly supporting an illegal industry and we suggest modification to the current legislation along with a central record keeping of such procedures to ensure greater compliance with the law and to reassure veterinarians that all operations can be conducted with a clear conscience.

The aim of this study was to analyse the current legal situation, and the effectiveness and possible flaws in the legislation. We analysed the role of veterinarians and the potential risks to the profession as well, and proposed improvements in the legislation of the United Kingdom and Slovakia.

\section{Docking and cropping in the past}

Historically, the removal of the tail was undertaken for many reasons in both countries, such as protection from being bitten in dog fighting sports, for increasing speed, strengthening the spine, and for prophylactic protection of the body during pest control from being bitten by brown rats (Rattus norvegicus) or from entanglement during shooting activities. Most surprisingly, docking was also conducted for the purpose of tax avoidance in the United Kingdom (Morton 1992).

Before the $19^{\text {th }}$ century in the United Kingdom, a tax was implemented on dogs used for pleasure purposes but not on dogs used for working purposes. To differentiate between the two categories of dogs, the tax was implemented on those with tails, while those without tails were not taxed (Morton 1992). Some areas had taxes that increased based on the length of the tail, however, it is noted that 'sport hunting' working dogs were then and are not now routinely docked. Such an anomaly may be due in part to the consideration of sport hunting as a pursuit of the wealthy, as opposed to other forms of rural hunting, such as with terriers, that were practiced by the poor and that involved dogs that were docked. In the past, tails docking was permitted in Slovakia, in accordance with the provisions of Government Regulation no. 109/1941 Coll., which issued more detailed regulations on the protection of animals against cruelty. The procedure could be done in dogs older than two weeks, after previous sedation.

The surgical cropping of the ears was traditionally used in dogs of fighting breeds to limit the possibility of the opponent biting the pinna or in dogs of pastoral breeds to reduce the possibility of a bear or wolf gaining a hold. It was also thought that dogs of working breeds with naturally hanging pinnae such as the Doberman pincher would suffer fewer infections or haematomas if the pinnae are cropped. At the time, the Lamarckian theory of acquired characteristic (Burkhardt 2013) was wildly upheld, therefore, it was commonly assumed that mothers who had been docked or cropped would be more likely to have puppies with shorter tails or ears. In Slovakia surgery was recommended for puppies (up to 12 weeks of age), due to less intense sensation of pain and trauma. After 4 months of age, this procedure was already considered painful, even if performed under full anaesthesia. This procedure had to be carried out by a veterinarian who already has the necessary experience and skills in the field in order for the ears to fit into the desired shape.

\section{The legal status in the United Kingdom and Slovakia}

The key piece of legislation governing tail docking and ear cropping in the EU is the European Convention for the Protection of Pet Animals. In the UK, the legislation involved 
is the Animal Welfare Act (2006). Provisions on ear cropping in Slovakia are included in the Act on Veterinary Care (2007 as amended).

Article 10 of the European Convention for the Protection of Pet Animals stipulates:

"Surgical operations for the purpose of modifying the appearance of a pet animal or for other non-curative purposes shall be prohibited and, in particular:

a) The docking of tails;

b) The cropping of ears;

c) Devocalisation;

d) Declawing and defanging."

Due to parts a) and b) of this article, the United Kingdom did not sign or ratify this treaty due to objections by dog breeders. Slovakia did not sign this treaty, either.

The elective docking of dogs in the United Kingdom is illegal to be conducted by anyone other than a licensed veterinary surgeon under the Veterinary Surgeons Act (1966). Veterinary surgeons may not legally conduct a tail docking procedure on a dog, except for two exceptions; medical necessity or upon the completion of a certificate stating the dog is to be used for working purposes and providing the necessary evidence by the owner of the puppy (Srinivasan 2013). In Slovakia the docking is regulated by the Act on Veterinary Care (2007 as amended), where the tail docking is possible only for a medical reason, or in case of puppies of recognized breeding standards that may have their tails docked up to age of 14 days.

Performing of ear cropping is illegal in the United Kingdom as applied to both laypeople and veterinary surgeons, unless for medical reasons. This procedure is prohibited in Slovakia, too.

Considering the changes in dog ownership over the last 300 years and the developments in veterinary medicine, the role and justification for tail docking and ear cropping has clearly changed. Greater understanding has been matched by the introduction of potentially controversial legislation regulating the situations in which a veterinary surgeon or lay person may perform these procedures. However, it has been suggested that current legislation does not adequately prevent the unnecessary surgical procedures it aims to regulate, while others argue that such regulation is unnecessary.

The Animal Welfare Act (2006) brings together legislation to protect the welfare of animals other than those living in the wild. It consolidated and superseded over twenty different pieces of legislation into one act, including the Protection of Animals Act (1934) and the Abandonment of Animals Act (1960). The corresponding Act for Scotland is the Animal Health and Welfare (Scotland) Act (2006).

The removal of a dog's tail is governed by article 6 , Removal of a Dogs' Tail and stipulates an offence is committed if a person removes the whole or part of a dog's tail or causes its removal by another person other than for the purpose of medical treatment.

An offence is also committed if a person who is responsible for a dog allows another person to remove a part of or all of the dog's tail without making any attempt to stop such action.

This act allows working dogs to be exempt from this regulation, provided they are no more than five days old and that a veterinarian has certified their working dog status.

As mentioned previously, a veterinarian must certify that the dog is to be used in law enforcement, activities of Her Majesty's armed forces, emergency rescue, lawful pest control, or the lawful shooting of animals and that it is of the following breeds or crosses:

- Hunt Point Retriever breed of any type or combination of types;

- Spaniel of any type or combination of types;

- Terrier of any type or combination of types.

Should a person be accused of an offence under these subsections, they may offer in their defence that they reasonably believed the dog was one of the animals to which these exemptions apply. 
An offence is also committed if a person owns a dog that has been docked but they have failed to ensure that is has been officially identified as such.

It is also an offence under this act to knowingly give false information to a veterinary surgeon in order to obtain a certificate allowing the docking of the dog to be conducted legally.

The act also covers the showing of dogs. It prohibits the showing of dogs at shows for which the public pay to attend, that have the tail wholly or partly removed, whether in England, Wales or elsewhere, provided it occurred after the commencement of the act. This allows those dogs to continue to be shown if they were docked prior to the act being implemented, even if that docking would now be prohibited.

Dogs that have been legally docked after the commencement of the act may only be shown for the purposes of demonstrating their working ability.

The current legislation in England and Wales and those EU countries that signed the European Convention for the Protection of Pet Animals treaty (ETS No. 125) but excluding the articles prohibiting tail docking, allows the docking of working dogs' tails for the prophylactic prevention of tail injuries (Diesel et al. 2010). In Scotland, the ban is extended to all dogs, working dogs included, but work is in place to bring Scotland in line with the rest of the UK.

This disjointed view between each country may be in part due to the difficulty with which it is possible to predict the future use of a puppy when it is at the legal docking age and due to the apparent lack of evidence of any protective benefit of tail docking.

\section{Protection of animals against cruelty in Slovakia}

In the Slovak Act on Veterinary Care (2007 as amended) in Section 22 "protection of animals" in point 2) there are rules that prohibit cruelty to the animal, which means any action except for a justified medical and approved procedural reason, in particular:

(a) causes permanent or long-term harm to the animal;

(b) without the use of anaesthetics, causes, if necessary, permanent or prolonged damage to non-renewable parts of the body, except for sterilization of females and castration of males, beak trimming and castration of cockerels, docking of tails in dogs with recognized breeding signs up to fourteen days of birth and docking of a part of the tail of small ruminants born on the territory of the Slovak Republic up to the age of eight days, which may be performed only by a person competent to perform those tasks.

There is a possibility of amputation of the auricle for health reasons. However, such a procedure should not be performed on both sides to ensure symmetry. In practice, we are also confronted with cases where ear cropping was indicated for alleged "health reasons" by veterinarians while health indication was not mentioned in the health file (Bugarský et al. 2008). Any exhibition of an animal that has previously undergone such an operation is forbidden. It is considered as promotion of cruelty on animals (Quartarone et al. 2012).

The removal of a dog's ears or tail for purely aesthetic purposes is illegal in the United Kingdom and Slovakia, too. The legislation on the cropping of ears is very clear, in that there are no exemptions to this rule, however, the rules governing tail docking may be open to exploitation.

\section{Regulation on the docking of working dogs in England}

Specific legislation, The Docking of Working Dogs' Tails (England) Regulations (2007), sets the specific requirements for evidence needed to be seen by a veterinarian in order to certify that a dog meets the requirements to be legally docked. This legislation 
was an amendment of an earlier draft which required the veterinarian to state that a puppy was likely to be used for working purposes. No veterinarian can make such a statement about a 5-day old puppy, therefore, such a declaration would be based on conjecture and not fact, therefore, the current legislation requiring the presentation of specific paperwork and the belonging of the puppy to a specific breed is much less open to interpretation.

However, it is beyond the scope of any veterinarian or dog breeder to predict the future temperament of a dog when it is less than five days old. Some dogs may not develop into adults with the attributes needed to be used for working purposes.

It also relies on the fact that the breeder will have sufficient interest from people who wish to buy the puppies to use them for working purposes, thus fulfilling their exemption criteria. This leaves them with two options; to keep all the puppies until a working home is found or to sell them to non-working companion animal homes instead. With the current wording of the law stating that the owner 'intends' to use them for working, there is in effect no breach of the regulations if intent did not match reality. Equally, given the use of the word 'intent' there is nothing to prevent a breeder from having a litter docked with the intention of increasing the marketability of his puppies rather than the specific intention of using the dogs for working purposes.

In order to certify that a dog is a working dog the veterinarian has to be presented with the dam, a signed declaration and one of the following:

- where the dog is presented for certification on behalf of one of Her Majesty's armed forces, armed forces identification;

- where the dog is presented for certification on behalf of a body providing an emergency rescue service, emergency rescue identification;

- where the dog is presented for certification on behalf of a police authority, police identification;

- where the dog is presented for certification on behalf of Her Majesty's Prison Service or of an organization contracted to provide custodial services on behalf of the Secretary of State, prison service identification;

- where the dog is presented for certification on behalf of Her Majesty's Revenue \& Customs, HMRC identification;

- evidence that the owner of the dog, or an agent or employee of the owner most likely to be using the dog, will be using the dog for work in connection with lawful pest control;

- a current shotgun or firearm certificate issued to the owner of the dog, or to the agent or employee of the owner most likely to be using the dog for work in connection with the lawful shooting of animals;

- a letter from a gamekeeper, a land-occupier (or his agent), a person with shooting rights, a shoot organizer, a club official, a person representing the National Working Terrier Federation, or a person engaged in lawful pest control, stating that the breeder of the dog whose tail is to be docked is known to them and that dogs bred by that breeder have been used (as the case may be) on their land, or in their shoot, or for pest control.

When completing the certificate, the veterinarian is not required to record the type of evidence they have seen. This helps to protect the privacy of the certificate holder in terms of their owning a gun license or their profession, but it does not allow the validation or audit of this certification scheme.

It is up to the veterinarian to make the decision based on the evidence presented to them but without any specific training to recognize a fraudulent or counterfeit certificate. It also prevents the implementation of a central database to monitor the validity of working dog certification. 


\section{Discussion}

The docking of a dog's tail is a veterinary procedure that can only be conducted by a veterinary surgeon, in line with the Veterinary Surgeon's act (1966) in the UK and the Act on Veterinary Care (2007, as amended) in Slovakia. These legislations mean that any dog with a docked tail presented to a veterinary surgeon can only have had this procedure legally performed by a veterinary surgeon. In order for the procedure to be legal, the dog must have been issued a certificate from the veterinarian that undertook the procedure to confirm that the dog meets the requirements for a legal elective tail docking and the correct evidence had been obtained.

Part of the certification procedure involves the insertion of a microchip, which is a legal requirement for all dogs in the UK. While the tail docking procedure can only legally take place before the dog reaches five days of age in the UK and up to fourteen days in Slovakia (according to breed standards), the insertion of a microchip has to occur before twelve weeks of age. Therefore, if a dog that has been docked is presented to a veterinarian for microchipping, they are required to request the certificate in order to add the microchip details to the relevant section and to sign the declaration in the United Kingdom.

Cropping the ears of dogs is illegal for both laypeople and veterinarians in the UK and Slovakia, too. However, the Royal Society for the Prevention of Cruelty to Animals (RSPCA) noted that between 2015 and 2017, reports of illegal ear cropping in dogs increased by 157 percent. While the overall number of reported cases was low, there is potential that some veterinarians are undertaking this procedure (Gaines 2018).

In an article in the Veterinary Record journal, the RSPCA have appealed for veterinary staff and those within the veterinary medicine field to report any suspicions they may have on this illegal practice (Gaines 2018).

Given the limited and specific circumstances in which a dog maybe legally docked within the UK and considering the total illegality of ear cropping, there may be times in which a veterinarian may be faced with a patient who he or she suspects may have undergone an illegal procedure. In the United Kingdom there is no legal requirement to report a suspected crime; however, there is a legal requirement to maintain client confidentiality. In the Slovak Republic if anyone is aware of the commission of the infringement, he/she is obligated to notify the competent authorities. On the other hand, there is a minimum of such notices.

\section{Monitoring of cases of tail docking or ear cropping}

Currently, in the UK and Slovakia, there is no central monitoring of tail docking or ear cropping of dogs. Therefore, there are no data for analysis as to the number of dogs docked, their breeds, and the eventual use of such dogs for working purposes for which they were allowed to be docked. The lack of any central database of this information means that if the current legislation is not fit for purpose there is no scientific way to analyse it and to advise policy makers. Anecdotal evidence is not suitable for basing amendments to legislation but may provide the foundation for the organisation of a systematic scientific review of the evidence and to design a non-biased study for further understanding.

Due to the lack of monitoring, veterinarians are currently unaccountable, even by their own governing body, the Royal College of Veterinary Surgeons (RCVS) in the UK or Chamber of Veterinary Surgeons in Slovakia. Only if a veterinarian is reported for malpractice, the RCVS (or Chamber of Veterinary Surgeons in Slovakia) seeks to initiate disciplinary measures, as opposed to proactively noticing any potential trends in a veterinarian's trends that may warrant investigation. Analysis was conducted in Germany where tail docking is illegal except for medical necessity (and a certificate of medical tail docking exemption is issued by the surgeon), comparing the breed distribution for medical tail docking with the breed distribution that presented medical tail docking exemption certificates to dog 
show personnel. No breed distribution was noted at a small animal medical hospital that conducted legal medically warranted tail docking procedures, however, a bias toward traditionally docked breeds, in particular the Doberman pincher was found for dogs shown professionally with a medical exemption for having a docked tail. This result is suggestive of either a greater propensity of veterinarians to decide to surgically remove a dog's tail rather than for a conservative treatment or to offer to dock the tails of dogs illegally, or of show judges preferentially selecting docked individuals for continuation and progression in the showing process. The latter reason is unlikely, given that further analysis of the medical reason and veterinarians involved suggested that either of the former reasons were more likely (Nolte 2006).

A central monitoring could possibly occur through the providers of microchip databases, upon which the tail docking or ear cropping procedures and the evidence for which those procedures were done could be registered. Microchipping is a legal requirement in the UK and Slovakia for all dogs, therefore, if the same evidence was required of all new owners of puppies that have undergone a docking procedure, as required by the breeder, unless the puppy was not suitable as a working dog or according to the breed standard, a true number of dogs that are docked under the provision they will be worked but without being used for the intended purpose would be known. This data may prove enlightening for policy makers if it was to be found that the number of dogs docked vastly outweighed the number of dogs that potentially benefited from the procedure, potentially bringing into question the ethicality as well as effectiveness of the current legislation.

\section{Conclusion}

The practice of evidence-based medicine underpins modern-day veterinary medicine, and as such, knowing that the rules veterinarians are obligated to follow are of benefit to the patient is key. The efficacy of legislation preventing illegal procedures in dogs in the United Kingdom and Slovakia are not monitored, therefore, it is not possible to state if the current legislation is fit for purpose. However, the lack of data on the subject should be seen as enough of a concern to warrant further research to shape governmental policy or to confirm that current legislation is suitable.

Further research must be aimed at understanding how many dogs undergo tail docking procedures and how many of these dogs end up being used for the purpose for which their tail docking exemption was granted. However, it is important that veterinarians are knowledgeable on the subject, not only in order to treat any complications or comorbidities but to also educate clients in these matters.

While the number of reported cases of illegal ear cropping in the UK is low and in Slovakia there were no reported cases of cosmetic intervention, the fact that there is an upward trend in this practice is concerning. The issue of prosecuting individuals for this is confounded by the ease with which dogs that have undergone this procedure can be imported. Therefore, the burden of proof rests on the admission of criminal activity by the keeper of such a dog.

While this act is legal in some countries and not in others, there is scope for a certification scheme to be implemented whereby the veterinarian that conducted the procedure may be able to issue a certificate that confirms that the procedure was conducted legally. In this way, it may make the process of monitoring for illegal activity more streamlined.

Education at veterinary universities on professional ethics and openly debating and discussing the issues at all professional levels may provide the cultural change within the profession to limit the availability of clinics willing to offer this procedure, however, greater scientific consensus is required to educate veterinarians and dog owners throughout the EU to facilitate the cultural change needed to assign these procedures to the history books. 


\section{References}

Abandonment of Animals Act. In C. 34. United Kingdom, 1960

Act on Veterinary Care N 39/2007 Coll as amended. Zbierka zákonov (Collection of Laws) 28: 1-104

Animal Health and Welfare (Scotland) Act. In Asp. 11. Scotland 2006

Animal Welfare Act. In C. 34. United Kingdom, 2006

Bennett P, Perini E 2003: Tail docking in dogs: a review of the issues. Aust Vet J 81: 208-218

Bugarský A et al. 2008: Dog, Owner and Law (In Slovak). UVMP Kosice, 104 p.

Burkhardt RW Jr 2013: Lamarck, evolution, and the inheritance of acquired characters. GSA 194: 793-805

Cosenza SF 1988: A technique for ear carriage correction in the dog. Mod Vet Pract 69: 158-160

Council of Europe 1987: The European Convention for the Protection of Pet Animals. European Treaty Series No. 125

Diesel G, Pfeiffer D, Crispin S, Brodbelt D 2010: Risk factors for tail injuries in dogs in Great Britain. Vet Rec 166: 812

Gaines S 2018: Reporting illegal ear cropping in dogs. Vet Rec 182: 577

Government Regulation No. 109/1941 Coll. laying down more detailed rules for the protection of animals against cruelty. Nařízení vlády (Government Regulation) 32: 341-360

Morton D 1992: Docking of dogs: practical and ethical aspects. Vet Rec 131: 301-306

Nolte I 2006: Analysis of veterinary certificates on tail docking in dogs. Deut Tierarztl Woch 113: 102-104

Pedersen N, Liu H, Theilen G, Sacks B 2013: The effects of dog breed development on genetic diversity and the relative influences of performance and conformation breeding. J Anim Breed Genet 130: 236-248

Protection of Animals Act. In C. 21. United Kingdom, 1934

Quartarone V, Voslářová E, Russo M, Doleželová P, Passantino A 2012: A comparison of laws preventing unnecessary canine cosmetic surgery in Italy and in the Czech Republic. Acta Vet Brno 81: 83-88

Srinivasan K 2013: The bio politics of animal being and welfare: dog control and care in the UK and India. Trans Inst Br Geogr 38: 106-119

The Docking of Working Dogs' Tails (England) Regulations. In No. 1120. England, 2007

Veterinary Surgeons Act. In C. 36. United Kingdom, 1966

Wayne RK, Ostrander EA 1999: Origin, genetic diversity, and genome structure of the domestic dog. BIOEEJ 21: $247-257$ 